\title{
Managing Knowledge Management: Identifying and Evaluating Enablers and Hinders from the Perspective of Practicing Managers from Tourism Sector in Sri Lanka
}

\author{
Mubarak Kaldeen
}

\begin{abstract}
The fundamental requirement of managing Knowledge Management (KM) successfully is to recognise the knowledge assets and manage it in the circumstance of overall organizational performance. The effective KM process influenced by knowledge-enablers and hindering factors. Hence, this study focuses to analyze the enablers and hinders that impact on KM practices and implementation in tourism sector in Sri Lanka. A total of 25 enablers and 20 hindering factors that could impact on KM implementation and practices have been identified based on a review of the related literature, and discussions with experts in the tourism filed. Random sampling method was employed and questionnaire survey carried out. 243 usable responses were received and results of statistical analysis of the responses revealed that the organisational infrastructure, management leadership and support, organisational culture, motivational aids, team building and knowledge variety, and use of internet and information technology have been identified as the most important enabler rank respectively for KM in tourism sector in Sri Lanka. Meantime, employee turnover, knowledge loses, failure to identify the variables of improving $K M$, use of inappropriate $K M$ strategies, over focus on IT and pressure for conformity were the most important hindering factors rank respectively for $\mathrm{KM}$ in tourism sector in Sri Lanka.
\end{abstract}

Keywords : Knowledge Management, knowledge-enablers, hindering factors of KM, Tourism Sector.

\section{INTRODUCTION}

Knowledge has turned out to be one of the basic main thrusts for organisational achievement and knowledge has been considered as solid asset like other resources and numerous associations are investigating the arena of information so as to enhance and support their aggressiveness and obtaining competitive advantages over their opponents. Knowledge Management (KM) has been given outstanding significance by practicing managers and scientists in different ventures. Understanding the boundaries and enablers is essential for the execution of $\mathrm{KM}$ in any foundations and a fitting treatment of these hindrances and enablers may guarantee compelling and proficient KM usage and an acknowledgment of guaranteed benefits like competitive advantage.

In the local setting, it was uncovered that in the underlying meetings had with rehearsing managers in the travel industry that the information has been overseen more casually than in

Revised Version Manuscript Received on 16 September, 2019.

* Correspondence Author

Mubarak Kaldeen, Department of Marketing Management, Faculty of

Management and Commerce, South Eastern University of Sri Lanka.

Oluvil, \# 32360, Sri Lanka. kmmubarak@seu.ac.lk formal routes, in such circumstance, a requirement was felt to viably actualize $\mathrm{KM}$ rehearses officially by creating empowering influences and overseeing preventing factors. In spite of the fact that KM is increasing more significance among the travel industry as an essential supporter of their prosperity, KM applications are moderately new in the travel industry, and some tourism industry establishments still don't have appropriate framework on KM rehearses, and numerous associations will in general join projects of $\mathrm{KM}$ without legitimate thought of the foundation's capacities and procedures to actualize KM rehearses. On the off chance that there is a operative KM enablers work in the tourism area, service superiority can be upgraded and the tourism sector data network through information sharing and creation will make competitive advantage. Be that as it may, aside from the early adopters other the tourism sector foundations had all the earmarks of being battling with usage of feasible KM technique. Subsequently, contributing and creating KM enablers fundamental for viable execution of KM practices to remain in front of the competition better [1]. Consequently, this investigation expects to recognize and assess essential and applicable barriers and enablers in overseeing KM in the tourism sector ventures in Sri Lanka. Distinguishing the enablers and barriers of compelling KM necessitates a comprehension of key movers, that could be recognized by taking a gander at the necessities, techniques and issues of powerful KM rehearses in a tourism industry fimrs. This investigation may give explicit understanding into the variables that hinder and enable compelling $\mathrm{KM}$ rehearses.

\section{ENABLERS OF KNOWLEDGE MANAGEMENT}

KM empowering influences allude to administrative designs which empower an association's learning $\mathrm{KM}$ and framework abilities [2]. The management funding has been known as an essential factor in effective change of authoritative activities, and knowledge management is the same. According to Chi et al., [3] demonstrated that adequacy of $\mathrm{KM}$ as it identifies with enhancing organisational execution in a roundabout way relies upon transformational leadership labours. Further investigations by the Shokri-Ghasabeh and Chileshe [4] likewise found the impact of the executives support on the capacity to catch exercises cultured is core factor of KM. The four essential destinations of $\mathrm{KM}$ frameworks ought to be: to improve knowledge transfer and access, to create repositories, to manage knowledge as an asset and to enhance knowledge environment. The requirement for $\mathrm{KM}$ is driven by knowledge

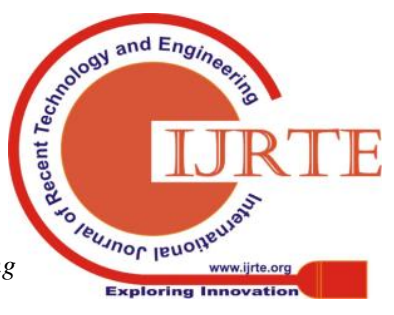


transfer and sharing, and the way to successful KM is met with boundaries coming about because of absence of standardized and integrated framework to catch, share and offer exchange information assets. A comprehension of the methods that could enable powerful KM practice is required so as to beat the boundaries and address the issue for viable KM.

There are numerous variables which are in charge of enablement of $\mathrm{KM}$ and hindering this empowerment procedure of $\mathrm{KM}$ and those components are perplexing in nature and bounteous in quantity. Numerous boundaries and empowering influences of $\mathrm{KM}$ execution have been recognized dependent on a survey of the related writing. KM methodologies may help different colleagues from multi-order to discover people with specific distinctive knowledge to support examine multifaceted issues to encourage in discovering proper arrangements. The management direction assumes a key job in impacting the achievement of KM. Pioneers are imperative in going about as good examples to embody the ideal conduct for KM. The introduction of $\mathrm{KM}$, arranging and planning for implementation are the most vital component for controlling knowledge within organisation. Administrative culture, another vital factor for fruitful KM, the application and reception of related advancements may have greater capacity in development and information sharing.

Another focal angle for executing KM is the advancement of suitable business framework. This may suggest setting up a lot of jobs and groups to perform information related undertakings. Fruitful KM entails the advancement platform to be taken by the workers to yield advantage of their organizations scholarly assets. In the event that people are not propelled to rehearse KM, no measure of speculation, framework and innovative mediation may make it compelling. Data sharing has been recognized as one of the critical empowering agent in numerous procedures for specialists to accomplish different destinations.

Information is seen as an asset inside association in KM key stance. Accentuation might be on the assortment of KM devices; and productivity and adequacy in information sharing among workers towards accomplishing competitive advantage. The way to accomplish $\mathrm{KM}$ is to instruct and prepare individuals about the thoughts and strategies utilized in KM. Individuals might be properly prepared so as to oversee learning. A reward framework may urge more representatives to take an interest in the usage of information the executives' system. Likewise, the writing survey found the accompanying empowering agents of $\mathrm{KM}$ and furthermore, the general and explicit focal point of the writing and the contextual investigation gave a more extensive and fascinating reflection on components identified with viable KM empowering activities.

According to Lopez-Nicolas and Merono-Cerdan [5] knowledge managed focus, knowledgeable workers \& matured technology and human resource management as empowering agents, meanwhile Wong [6] and Lopez-Nicolas and Merono-Cerdan [5] found financial inspiration and economic returns and education and training as empowering influences while the management control distinguished by Teece [7] and Bernus et al [8] discovered reuse of learning stores essential for the execution of KM. Yang [9] considered and found the accompanying components as empowering influences which effect on the KM rehearses in an association; representatives' learning, compensating the

worker, inventive personalities and consolation to conceptualizing while Wong [6] and Khalghani et al [10] found data sharing society, KM initiative and organisational culture as empowering agents of KM. Additional, information sharing [6],[9],[10], effectiveness in knowledge sharing and efficiency [10],[9], utilization of novel information technology and internet technology [5],[10], assets [7],[6], knowledge variety and team building [6],[11], decision support network [11] and information coordination [12],[11] were assessed and found as empowering influences. Toit and Steyn (2011) recognized and assessed settling on powerful choices, business targets, core business forms and key introduction, arranging and detailing as crucial empowering agents while Wong [6] considered organisational infrastructure, the board administration and support, persuasive guides, business and innovation technique and critical thinking conduct and found as essential empowering influences for the usage of KM.

\section{HINDERS IN KNOWLEDGE MANAGEMENT}

KM boundaries are those factors which block the empowerment of a vital idea for the development of any association'. From the writing survey and master assessments, writing audit came about into distinguishing proof of different boundaries in KM process execution.

It has been perceived and understood that experts and specialists with various ability learning and from various order may experience issues setting up a typical dialect while interfacing, in rehearsal, KM activities have been incited by a few variables, among them representative turnover, quick firm development and weights to decrease process durations have been observed vital to be managed cautiously [13] However, numerous KM frameworks have been unsuccessful, and disappointment rates of over $80 \%$, because of various reasons, for example, an over spotlight on IT, wrong KM procedures or obliviousness of KM results [14] Rate and level of progress may likewise influence the execution and results of information the organisational procedure in light of abstract translation of people and gatherings that changes the information (past) into activities and exhibitions [15]. Talented area expert may change their work rehearses after some time. On the off chance that clients can't alter a framework at use time to help new practices and rising data, they will be bolted into the old examples of utilization [16].

It has been discovered that utilizing the external portrayals uncovered and concentrates dialogs on, pertinent factors of the encircling and comprehension of the issue being contemplated, for example, tacit of mind, perspectives and qualities [16]. Non-serene utilization of KM may likewise be a hindrance of the procedure. It has been perceived that IT usage alone does not result in the achievement of knowledge management [15]. KM might be a system within which all business procedures might be viewed as knowledge 'transformation and creation' forms. The key purpose of KM is to collect the unsaid learning dwelling in people and make it an association's advantage, as opposed to individuals. The accompanying components have been recognized through the writing as a hindering factors for the viable execution of KM rehearses.

According to Gray [17], he found in his examination, weight for congruity, issue of normal dialect required 
working under limited levelheadedness and increments in knowledge decent variety as hindering elements meanwhile Leidner [13] identified that lobor turnover, hasty firm development and weight of losing staff results as essential impedes to be considered before the application of $\mathrm{KM}$ rehearses. KM loses, utilization of improper KM methodologies, numbness of KM results obliviousness about $\mathrm{KM}$ enhancing factors were found to critical preventing factors by [5]. According to Malhotra [15], he evaluated and identified the accompanying variables as imperative ruining factors on KM rehearses; actions \& constructed meanings, degree of change and rate, non-serene reason by human, achieving commitment, self-control for creativity and unconventional means of terror. Meantime, Wong [6] discovered execution of just IT and giving more spotlight on it has turned into a blocking variable to KM. Study of Ostwald [16] uncovered that associating new and old learning, putting communities in charge, creating shared understanding, catching data at use time and guarantees were obstructing the compelling usage of $\mathrm{KM}$ rehearses in associations.

\section{METHODOLOGY}

This empirical study was conducted in the tourism sector in Sri Lanka and the target respondents were the managerial level employees or any employee accountable for KM system in their institution. Sampling technique was the probability sampling and the respondents were randomly selected from the list of registered institutions under the SLTDA. Questionnaire survey method was employed to assess the significance of the KM enablers and hinders. The questionnaires were administered through drop and pickup method and email method. The importance of enablers and hinders were focused and assessed the perception of employees on the knowledge management implementation process. The degree of importance of each enablers and hinders in the knowledge management implementation was rated by the employees based on a 5-Point Likert scale. Although 350 questionnaires were distributed only 243 usable responses were received. The literature review and experts opinion revealed that there were various enablers and hinders impact on the tourism sector's KM implementation and performance. Eventually, 25 enablers of KM applicable to tourism sector were classified, whereas 20 hinders were selected for this study and proceeded with statistical analysis.

\section{RESULTS AND DISCUSSION}

The results of statistical analysis as shown in the table 1, illustrate that the organisational infrastructure, management leadership and support, organisational culture, motivational aids, team building and knowledge variety, and use of internet and information technology have found to most imperative enabler ranked respectively for $\mathrm{KM}$ in tourism sector in Sri Lanka. Meantime, rewarding the employee, creative minds, encouragement to brain storming, knowledge management initiative, matured technology, making effective decisions, and business objectives have been found as less important enablers for KM in tourism sector.

Table 1: Descriptive Statistics for Knowledge Management Enablers

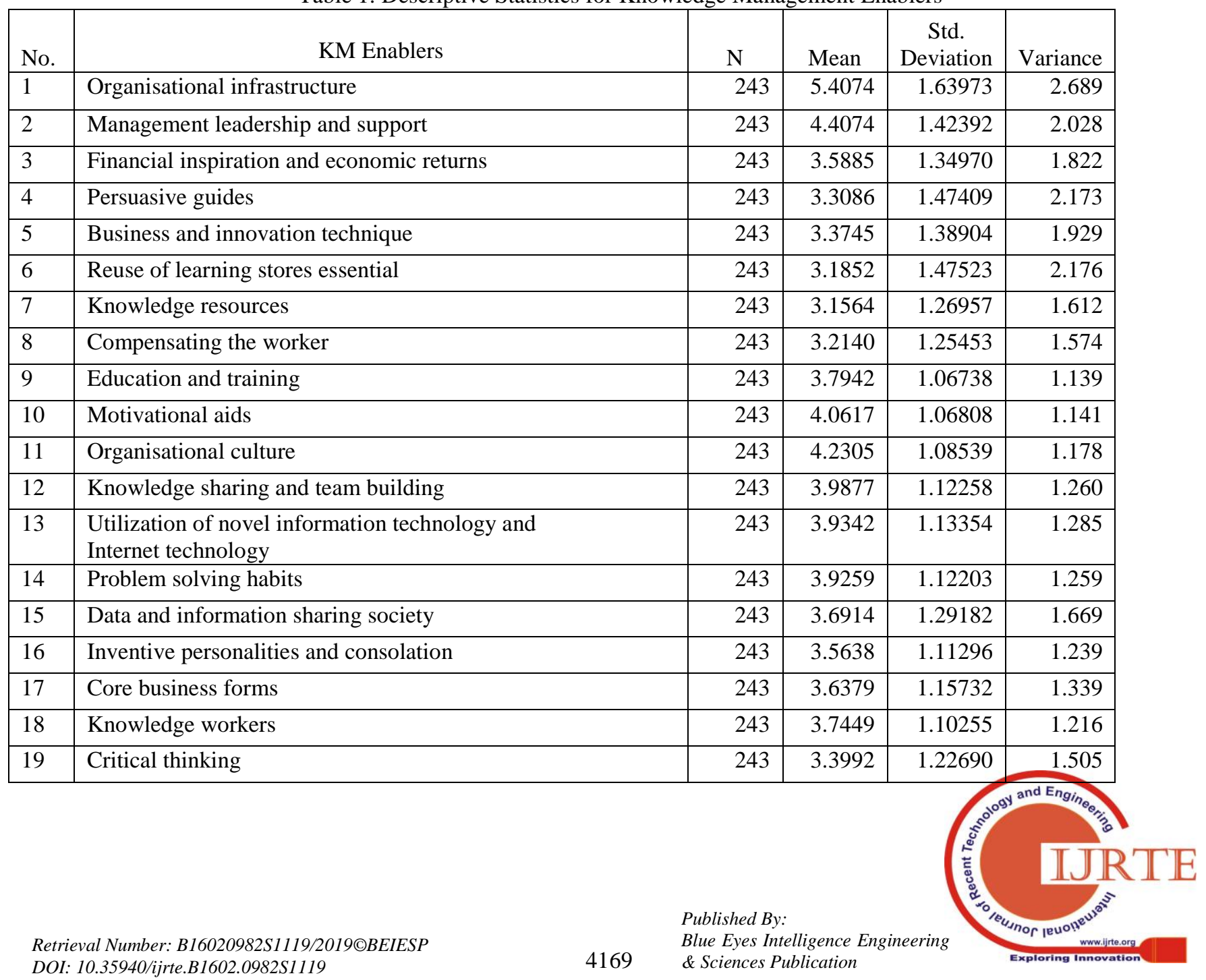


Managing Knowledge Management: Identifying and Evaluating Enablers and Hinders from the Perspective of Practicing Managers from Tourism Sector in Sri Lanka

\begin{tabular}{|l|l|r|r|r|r|}
\hline 20 & Decision support network & 243 & 3.8683 & 1.08290 & 1.173 \\
\hline 21 & Strategic orientation & 243 & 3.6420 & 1.13518 & 1.289 \\
\hline 22 & Business targets & 243 & 3.2181 & 1.21533 & 1.477 \\
\hline 23 & Employees' knowledge & 243 & 3.7695 & 1.11172 & 1.236 \\
\hline 24 & Information coordination & 243 & 3.7490 & 1.12758 & 1.271 \\
\hline 25 & Effectiveness in knowledge sharing and efficiency & 243 & 3.6420 & 1.24955 & 1.561 \\
\hline
\end{tabular}

The results of statistical analysis as shown in the table 2 of the responses of questionnaire survey to rate the importance of hindering factors in managing knowledge in tourism sector found that employee turnover, knowledge loses, ignorance about KM improving variables, use of inappropriate $\mathrm{KM}$ strategies, over focus on IT and pressure for conformity were the most hindering factors rank respectively for $\mathrm{KM}$ in tourism sector in Sri Lanka whereas, rate and degree of change, non-peaceful purpose by human, self-control for creativity, and achieving commitment have been identified as less important hindering factors for KM in tourism sector.

Table 2: Descriptive Statistics for Knowledge Management Hinders

\begin{tabular}{|c|c|c|c|c|c|}
\hline No & KM Hinders & $\mathrm{N}$ & Mean & $\begin{array}{c}\text { Std. } \\
\text { Deviation }\end{array}$ & Variance \\
\hline 1 & Over focus on IT & 243 & 6.27 & .945 & .893 \\
\hline 2 & Work pressure & 243 & 6.15 & .920 & .846 \\
\hline 3 & Knowledge loses & 243 & 6.41 & .883 & .780 \\
\hline 4 & Labour turnover & 243 & 6.49 & .859 & .739 \\
\hline 5 & Promises & 243 & 3.67 & .744 & .554 \\
\hline 6 & Conflict behaviours & 243 & 3.56 & .760 & .578 \\
\hline 7 & Hasty firm development & 243 & 3.39 & .755 & .570 \\
\hline 8 & Working environment & 243 & 3.66 & .858 & .737 \\
\hline 9 & Lack of knowledge shared culture & 243 & 4.65 & 1.093 & 1.194 \\
\hline 10 & Inability of KM implementation & 243 & 3.79 & .849 & .720 \\
\hline 11 & Issue of working dialect & 243 & 5.84 & 1.021 & 1.042 \\
\hline 12 & Ignorance of KM benefits & 243 & 5.84 & 1.021 & 1.042 \\
\hline 13 & Knowledge diversity & 243 & 5.87 & .966 & .933 \\
\hline 14 & Self-control for creativity & 243 & 5.81 & .964 & .928 \\
\hline 15 & Associating with old learning & 243 & 5.58 & .973 & .948 \\
\hline 16 & Numbness of KM results obliviousness & 243 & 5.66 & 1.217 & 1.482 \\
\hline 17 & Degree of change & 243 & 6.14 & 1.059 & 1.121 \\
\hline 18 & Utilization of inappropriate KM strategies & 243 & 6.33 & .898 & .807 \\
\hline 19 & Pressure for conformity & 243 & 6.19 & .680 & .462 \\
\hline 20 & Ignorance about KM improving variables & 243 & 6.53 & 669 & .448 \\
\hline
\end{tabular}

\section{CONCLUSIONS AND RECOMMENDATIONS}

Effective KM process for any institution requires enablers for its implementation. The enablers are considered as the assets which are helpful to manage KM process. It was found that the managers from the institutions have lack of awareness on the significance and hindering variables that contribute to improve KM programmes. This research focused on identifying and evaluating the enablers and hindering factors that impact on KM implementation in tourism sector. Effective KM implementation also depend on an apposite management of KM enablers and hinders. Hence, it is the duty of top management to apprehend and support through facilitating infrastructure and creating KM culture, enhanced use of internet and information technology for the implementation of $\mathrm{KM}$ in their institutions. Further, KM initiatives can be more supported by providing training and education and problem solving behavior.

In practice, KM initiatives have been hindered by several factors, among them employee turnover and loss of knowledge have been found important to be dealt with carefully in tourism sector. Institutions have to support with new system to suit the skilled dominion proficient whom may change their work practices over time. The above said initiatives are paramount important to manage $\mathrm{KM}$ implementation for tourism sector in Sri Lanka.

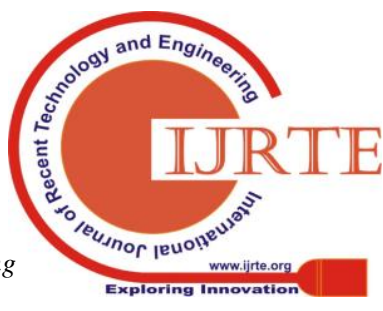




\section{REFERENCES}

1. P. Heisig, O.A. Suraj, K. Aino, K. Cosmas, P.A. Gregorio, and F.E. Nasser, Knowledge management and business performance: global experts' views on future research needs. Journal of Knowledge Management, 2016; 20(6), pp.1169- 1198.

2. S.B. Sangeeta, C. Sumedha and R. Aparna, Impact of Knowledge Management Capabilities on Knowledge Management Effectiveness in Indian Organizations, The Journal for Decision Makers, 2015; 40(4) pp.421-434.

3. H.K. Chi, C.H. Lan and B. Dorjgotov, The moderating effect of transformational leadership on knowledge management and organizational effectiveness. Social Behavior and Personality, 2012; 40(6), pp.1015-1024

4. M. Shokri-Ghasabeh, C. Nicholas, "Knowledge management: Barriers to capturing lessons learned from Australian construction contractors perspective", Construction Innovation, 2014; Vol. 14 Issue: 1, pp.108-134, https://doi.org/10.1108/CI-06-2013-0026.

5. K. Yew Wong, Critical success factors for implementing knowledge management in small and medium enterprises. Industrial management \& Data systems. 2005 Apr 1;105(3): pp.261-79.

6. D.J. Teece, Strategies for managing knowledge assets: the role of firm structure and industrial context. Long range planning. $2000 \mathrm{Feb}$ $1 ; 33(1)$ : pp.35-54.

7. P. Bernus, J. Blaiewicz, G. Schmidt and M. Shaw, Designing virtual learning centres, international Handbook on Information System, Springer-Verlag, Berlin Heidelberg, 2002.

8. J. Yang, The knowledge management strategy and its effect on firm performance: A contingency analysis. International Journal of Production Economics. 2010 Jun 1;125(2): pp.215-23.

9. A. Khalghani, H. Reshadatjoo and M. Iran-nejad-parizi, A study on organizational culture, structure and information technology as three KM enablers: A case study in five Iranian medical and healthcare research centers. Management Science Letters. 2013;3(1): pp.147-58.

10. N. Wasem and A. Jayant, A framework of knowledge integration with decision support system for educational environment: a case study. InProceedings of International Conference on Smart Technologies for Mechanical Engineering 2013 pp. 369-377.

11. A. Du Toit and P. Steyn, Knowledge management as a strategic management tool at a South African enterprise, 2011.

12. D. Leidner, Editorial, Journal of Strategic information System, 2000 Vol. 9, pp.101-105.

13. J. Storey and E. Barnett, Knowledge management initiatives: learning from failure. Journal of knowledge management. 2000 Jun 1;4(2): pp.145-56.

14. Y. Malhotra, Features-Enabling Knowledge Exchanges for E-Business Communities-Unsuccessful attempts of E-commerce models have increased interest in online communities as critical enablers of E-business. Information Strategy-Boca Raton. 2002;18(3): pp.26-31.

15. J. Ostwald, Knowledge construction in software development: The evolving artifact approach. Ph. D. Dissertation, Department of Computer Science, University of Colorado at Boulder. 1996.

16. P.H. Gray, The effects of knowledge management systems on emergent teams: towards a research model. The journal of strategic information systems. 2000 Sep 1;9(2-3): pp.175-91 